\title{
PENGARUH FAKTOR INDIVIDU DAN SOSIAL TERHADAP KEPUTUSAN MENGGUNAKAN \\ (Survei pada Pengguna Aplikasi Mobile Messaging di Kota Bandung)
}

\author{
Lidya Aprilia \\ Universitas Pendidikan Indonesia \\ lidyaaprilia@student.upi.edu \\ Lili Adi Wibowo \\ Universitas Pendidikan Indonesia \\ liliadiwibowo@upi.edu
}

\begin{abstract}
ABSTRAK
Komunikasi merupakan dasar kebutuhan manusia, Hal tersebut yang membuat luasnya pangsa pasar di berbagai kawasan termasuk di Kota Bandung. Perusahaan Aplikasi Blackberry Messanger, WhatsApp, Line, KakaoTalk, dan WeChat memiliki berbagai tawaran produk berupa fitur yang attractive. Perusahaan yang cerdas adalah perusahaan yang mampu melihat tahapan keputusan menggunakan penggunanya. Dengan memahami tahapan tersebut, agar dapat bersaing dengan unggul perusahaan dituntut untuk menciptakan produk yang sesuai dengan keinginan dan kebutuhan penggunanya. Salah satu cara yang dapat dilakukan adalah mengetahui perilaku pengguna dengan dasar faktor individu dan sosial.

Penelitian ini bertujuan untuk (1) mengetahui gambaran faktor individu pada pengguna Aplikasi Mobile Messaging di Kota Bandung, (2) mengetahui gambaran faktor sosial pada pengguna Aplikasi Mobile Messaging di Kota Bandung (3) mengetahui gambaran tingkat keputusan menggunakan pada pengguna Aplikasi Mobile Messaging di Kota Bandung, (4) mengetahui temuan mengenai seberapa besar pengaruh faktor individu dan sosial terhadap keputusan menggunakan pada Aplikasi Mobile Messaging di Kota Bandung. Objek/unit analisis dalam penelitian ini adalah pengguna Aplikasi Mobile Messaging di Kota Bandung. Variabel eksogen $\left(\mathrm{X}_{1}\right)$ dalam penelitian ini adalah faktor individu dan $\left(\mathrm{X}_{2}\right)$ adalah faktor sosial, serta variabel endogen (Y) pada penelitian ini adalah keputusan menggunakan. Jenis penelitian yang digunakan adalah deskriptif, verifikatif, dan metode yang digunakan adalah explanatory survey dengan teknik simple random sampling, dengan jumlah sampel sebanyak 400 pengguna. Teknik analisa data yang digunakan adalah Structural Equation Model dengan alat bantu software komputer SPSS 21.0 dan AMOS 22.0. Hasil yang diperoleh dalam penelitian menyatakan bahwa faktor individu berpengaruh langsung terhadap keputusan menggunakan Aplikasi Mobile Messaging di Kota Bandung dengan nilai sebesar 0.625 atau $62.5 \%$. Dari penelitian terhadap pengujian hipotesis dapat diketahui bahwa faktor individu memiliki pengaruh yang positif terhadap keputusan menggunakan pada pengguna. Selain itu pengaruh antara faktor sosial dengan keputusan menggunakan yaitu dengan pengaruh hubungan langsung sebesar 0.306 atau $30.6 \%$. Dari penelitian terhadap pengujian hipotesis dapat diketahui bahwa faktor sosial memiliki pengaruh yang positif terhadap keputusan menggunakan pada pengguna.Berdasarkan hasil penelitian yang memberikan nilai kontribusi paling besar dalam pengaruhnya kepada keputusan menggunakan pada dimensi faktor individu adalah belief and attitudes dan personality, sedangkan pada faktor sosial yaitu references groups. Penulis merekomendasikan agar perusahaan lebih memahami faktor individu serta faktor sosial sebagai salah satu dasar untuk membuat produk dan meningkatkan keputusan menggunakan Aplikasi Mobile Messaging di Kota Bandung.
\end{abstract}

\section{Kata kunci: Faktor Individu, Faktor Sosial, Dan Keputusan Menggunakan}


Perkembangan teknologi di bidang informasi dan komunikasi yang didukung oleh sumber daya manusia yang lebih maju, dilihat secara global mampu memberikan manfaat dan merubah pemenuhan kebutuhan secara menyeluruh. Saat ini, masyarakat selalu menginginkan segala sesuatu yang instant, salah satunya dalam hal komunikasi. Tuntutan masyarakat dan perkembangan pasar dijadikan peluang serta core bisnis bagi perusahaanperusahaan yang bergerak dalam bidang telekomunikasi. Masing-masing perusahaan saling berlomba dengan terus berinovasi untuk menghasilkan product yang bermanfaat dan aplikasi mobile messaging merupakan product yang dihasilkan dari perkembangan pemikiran dan teknologi.

Aplikasi mobile messaging adalah sektor paling kompetitif saat ini, karena memiliki peran penting dalam platform mobile sebagai layanan berkomunikasi, yang dapat diunduh melalui toko aplikasi dengan pilihan gratis atau berbayar. Tingkat pertumbuhan aplikasi mobile messaging yang didukung dengan perkembangan smartphone dan akses internet yang lebih baik mampu meningkatkan eksistensinya, berdasarkan data yang dihasilkan oleh Flurry Analitycs, di tahun 2013 aplikasi yang masuk dalam kategori pesan dan media sosial adalah yang paling dominan digunakan. Kenaikan kedua aplikasi tersebut mencapai hingga $203 \%$, dibandingkan aplikasi lainnya seperti games 66\%, music dan hiburan $78 \%$ serta news, magazines $31 \%$ (Sumber : http://chip.co.id/ di akses pada 18 Februari 2014 15.00 PM). Fenomena aplikasi mobile messaging terjadi secara global, hal ini terlihat pada perolehan pengguna yang tersebar diberbagai negara seperti yang tertera pada Tabel 1

TABEL 1

\section{TINGKAT SEBARAN PENGGUNA} APLIKASI MOBILE MESSAGING

\begin{tabular}{|c|c|c|c|}
\hline Peringkat & $\begin{array}{c}\text { Aplikasi } \\
\text { Mobile } \\
\text { Messaging }\end{array}$ & $\begin{array}{c}\text { Jumlah } \\
\text { Pengguna }\end{array}$ & $\begin{array}{c}\text { Dominasi } \\
\text { Negara } \\
\text { (Pengguna) }\end{array}$ \\
\hline 1 & WeChat & 600 & China, Asia \\
\hline 2 & WhatsApp & 590 & $\begin{array}{c}\text { Amerika, } \\
\text { jerman, } \\
\text { Meksiko, } \\
\text { India, } \\
\text { Spanyol, } \\
\text { Brazil, Afrika } \\
\text { Selatan, dan } \\
\text { Indonesia }\end{array}$ \\
\hline 3 & $\begin{array}{c}\text { Facebook } \\
\text { Messanger }\end{array}$ & 500 & $\begin{array}{c}\text { Amerika } \\
\end{array}$ \\
\hline 4 & Line & 300 & $\begin{array}{c}\text { Jepang, } \\
\text { Thailand, } \\
\text { Taiwan }\end{array}$ \\
\hline 5 & Viber & 200 & $\begin{array}{c}\text { Israel, India, } \\
\text { Ciprus }\end{array}$ \\
\hline
\end{tabular}

\begin{tabular}{|c|c|c|c|}
\hline 6 & SnapChat & 100 & $\begin{array}{c}\text { Amerika, } \\
\text { Inggris, } \\
\text { Norwegia }\end{array}$ \\
\hline 7 & KakaoTalk & 100 & Korea Selatan \\
\hline
\end{tabular}

Sumber : http://wmpoweruser.com/ diakses pada 20 Agustus 2014 10:00 PM

Berdasarkan Tabel 1.1 terdapat beberapa aplikasi mobile messaging yang mendominasi di dunia. Namun, Indonesia belum mampu mendominasi di aplikasi mobile messaging lainnya. Setiap negara di dunia memberikan kontribusinya bagi perkembangan pengguna aplikasi mobile messaging. perbedaan selera, tingkat aktivitas dan kebutuhan yang menyebabkan aplikasi mobile messaging memiliki jumlah pengguna yang berbeda.

Hanya sebagian masyarakat di Indonesia yang menggunakan aplikasi mobile messaging untuk pemenuhan kebutuhan dan aktivitas. Hal ini diakibatkan oleh penggunaan aplikasi pemilik smartphone di Indonesia masih rendah dibandingkan pengguna dari negara Asia dan secara khusus di negara Asia Tenggara. Setidaknya itu terlihat dari laporan Nielsen Informate Mobile Insight yang mencakup Indonesia, Malaysia, Filipina, dan Thailand belum lama ini. Dari hasil riset terlihat penggunaan aplikasi paling sering adalah di Malaysia (66 menit per hari), diikuti oleh Thailand (46 menit per hari), Filipina (41 menit per hari) dan Indonesia (40 menit per hari) (Sumber : http://www.indotelko.com diakses pada 23 Februari 2014 3:50 PM).

Tergolong penggunaan aplikasi yang rendah namun Indonesia termasuk negara yang memiliki jumlah penduduk yang banyak, pada tahun 2011 saja, jumlah penduduk Indonesia mencapai 243.801.639 juta jiwa. Hal ini yang menjadikan Indonesia tetap menjadi target pasar yang diperhitungkan bagi perusahaan aplikasi mobile messaging. Pada Tabel 1.1 Indonesia kurang mampu berkontribusi dalam perolehan jumlah pengguna aplikasi mobile messaging lainnya, namun menurut data yang diperoleh dari lembaga survei global Nielsen, terdapat beberapa aplikasi mobile messaging yang disukai dan dicari oleh masyarakat Indonesia, tertera pada Tabel 2 berikut ini:

TABEL 2

10 APLIKASI YANG DISUKAI DI INDONESIA

\begin{tabular}{|l|l|}
\hline Peringkat & \multicolumn{1}{|c|}{ Nama Aplikasi } \\
\hline 1. & Facebook \\
\hline 2. & BlackberryMessanger \\
\hline 3. & WhatsApp \\
\hline 4. & Line \\
\hline 5. & WeChat \\
\hline 6. & Top Eleven \\
\hline 7. & Google Playstore \\
\hline 8. & Twitter \\
\hline 9. & Youtube \\
\hline
\end{tabular}




\begin{tabular}{|l|l|}
\hline Peringkat & \multicolumn{1}{|c|}{ Nama Aplikasi } \\
\hline $\mathbf{1 0}$. & Blackberry world \\
\hline
\end{tabular}

Sumber : http://dailysocial.net/ diakses pada 12 Maret 2014 20:00 PM

Data yang diungkapkan sebelumnya memperlihatkan ketidaksesuaian antara penggunaan aplikasi yang masih rendah dan tingkat perkembangan aplikasi mobile messaging yang cukup tinggi. Hal ini terjadi karena terdapat tingkat perbedaan antara iklim pasar dengan trend pengguna.

Iklim pasar saat ini merupakan hal yang menguntungkan bagi perusahaan mobile messaging. Masing-masing perusahaan menerapkan berbagai macam program pemasaran untuk memperoleh pangsa pasarnya. Pada Tabel 1.2 diatas terjadi tingkat persaingan bagi perusahaan mobile messaging yang diminati oleh masyarakat Indonesia seperti Blackberry Messanger, WhatsApp, Line, KakaoTalk, dan WeChat. Tabel 3 menunjukkan persaingan diantara masing-masing perusahaan dengan tingkat persentase dan jumlah penggunanya pada tahun 2014 di Indonesia, berikut ini.

TABEL 3

JUMLAH PENGGUNA APLIKASI MOBILE MESSAGING TAHUN 2014 (Blackberry Messanger, WhatsApp, Line, WeChat, KakaoTalk)

\begin{tabular}{|l|l|c|}
\hline No & $\begin{array}{l}\text { Aplikasi Mobile } \\
\text { Messaging }\end{array}$ & $\begin{array}{l}\text { Jumlah Pengguna atau } \\
\text { Persentase Pengguna } \\
\text { (dalam juta jiwa) }\end{array}$ \\
\hline 1. & $\begin{array}{l}\text { Blackberry } \\
\text { Messanger }\end{array}$ & $37 \%$ \\
\hline 2. & WhatsApp & $43 \%$ \\
\hline 3. & Line & 30 \\
\hline 4. & WeChat & 31 \\
\hline 5. & KakaoTalk & 16 \\
\hline
\end{tabular}

Sumber : http://www.liputan6.com/ diakses pada 20 Agustus 201420.00 PM

Data tersebut memperlihatkan eksistensi masing-masing aplikasi mobile messaging, untuk perolehan persentase pengguna. Trend pasar seperti ini terjadi pada setiap daerah di Indonesia, berdasarkan survei Ericsson Consumer Lab Analytical Platform 2013 dengan menggunakan 2.053 responden di sembilan provinsi di DKI Jakarta, Jawa Barat, Jawa Tengah, Jawa Timur, Banten, Sumatera Utara, Kepulauan Riau, Kalimantan Timur, dan Sulawesi Selatan, menunjukkan Blackberry Mesanger, WhatsApp, WeChat, KakaoTalk, Line, mencapai $56 \%$ dari total responden pengguna smartphone (Sumber www.bakriebrothers.com diakses pada 23 Maret 201420.00 WIB).

Jawa Barat yang diwakilkan dengan pusat pemerintahannya di Bandung memiliki traffic seluler tertinggi dibandingkan dengan kota besar lainnya di Indonesia, dengan perolehan setiap harinya sebesar $30 \%$ sampai 50\% (Sumber : http://www.postel.go.id/ diakses pada 28 Maret 201420.00 WIB). Data tersebut mengindikasikan bahwa untuk penggunaan aplikasi mobile messaging, Bandung memiliki potensi yang tinggi.

Pengguna atau konsumen memiliki karakteristik dan tingkat perbedaan dalam hal memilih dan menggunakan Blackberry Messanger, WhatsApp, KakaoTalk, Line, dan WeChat. Perusahaan yang cerdik akan mencoba untuk memahami pelanggan atau konsumen, dengan memperhatikan tahapan sebelum melakukan keputusan menggunakan yaitu pengalaman dalam belajar, memilih, menggunakan, dan bahkan membuang atau tidak menggunakan kembali, seperti yang diungkapkan oleh Kotler dan Keller (2012:166) "Smart companies try to fully understand customers' buying decision process-all the experiences in learning, choosing, using, and even disposing of a product".

Memperhatikan konsumen sebagai faktor utama, perusahaan perlu mengetahui perilaku konsumen dalam melakukan keputusan menggunakan, karena hal tersebut sangat penting untuk pemasar atau perusahaan, sehingga secara efektif dapat mengembangkan strategi yang diterapkan. Dalam hal ini Engel, Blackwell dan Miniard dalam Hawkins (2004:130) mengemukakan bahwa, perilaku konsumen memiliki model yang membentuknya, yaitu proses yang didalamnya terdapat lima tahapan dan faktor-faktor yang mempengaruhi tahapan-tahapan itu terdiri dari internal dan eksternal. Homer dan Kahle (1988) mengemukakan hal yang sama bahwa seorang individu dalam melakukan keputusan menggunakan dipengaruhi oleh internal oriented, eksternal oriented

Internal oriented adalah dorongan yang datang dari dalam diri seseorang yang mampu mempengaruhi pikiran, dan tindakan, sedangkan eksternal oriented pengaruh yang datang dari lingkungan sekitarnya. hal tersebut yang harus diperhatikan oleh perusahaan, seperti yang dikemukakan oleh Matin Khan (2006:4), "Having understood his different behaviours which require an in-depth study of their internal and external environment". Kemampuan memahami konsumen dalam melakukan keputusan menggunakan yang didasari pada internal oriented dan eksternal oriented merupakan hal cukup membingungkan bagi perusahaan, untuk memecahkan hal tersebut maka difokuskan dalam internal oriented terdapat faktor individu, sedangkan eksternal oriented terdapat faktor lingkungan organisasi atau sosial, seperti penelitian 
sebelumnya yang dikemukakan oleh Ferrell and Gresham (1985) dalam modelnya, "That a marketer will experience ethical dilemmas, the marketer's solution to the ethical dilemmas is influenced by individual factors and organizational factors such as opportunity and significant others."

Aplikasi Blackberry Messangger, WhatsApp, KakaoTalk, Line dan WeChat perlu memperhatikan faktor- faktor yang mempengaruhi individu yaitu information processing, motivation, belief and attitudes, personality, life style, life cycle dan faktor sosial yang terdiri dari culture, social class, geo demographics, reference groups (Jobber 2010).

Aplikasi Blackberry Messangger melihat faktor individu pengunanya di Bandung dengan hadir pada setiap platform. Untuk menyentuh segi faktor sosial, Blackberry Messanger memperbaharui tampilan dengan melakukan update setiap bulannya, sehingga mampu menawarkan fitur yang sesuai dengan tuntutan lingkungan sekitar penggunanya.

WhatsApp selalu memperhatikan faktor individu masyarakat Bandung yang menyukai hal instant dan cepat, dengan memperkaya fitur serta kecepatan transaksi informasi, dan tetap pada prinsipnya untuk tidak menggunakan iklan maupun fitur games, serta memperhatikan faktor sosial dengan memberikan penawaran pembuatan group yang lebih dari 20 orang yang disukai dan diminati segmentasi remaja.

Line dan KakaoTalk yang melihat faktor individu masyarakat Bandung yaitu menerapkan program pemasaran berupa iklan. WeChat yang melihat faktor individu menerapkan mindset untuk selalu berkomunikasi menggunakan mobile messaging dengan tagline utamanya yaitu "We Love We Share and WeChat". Dalam memperhatikan faktor sosial terutama segmentasi remaja, WeChat menawarkan fitur yang terlihat friendly, pemilihan brand ambassador serta soundtrack yang disukai, oleh kalangan remaja

3Berdasarkan uraian tersebut program pemasaran yang diterapkan perusahaan aplikasi mobile messaging sudah menyesuaikan dengan faktor individu dan sosial, namun dalam pelaksanaannya masih terdapat beberapa program yang tidak berjalan sesuai harapan, hal ini diperlihatkan dengan perolehan pengguna yang belum menyuluruh. Maka peneliti merasa perlu untuk melakukan penelitian mengenai "Pengaruh Faktor Individu dan Sosial terhadap Keputusan Menggunakan (survei terhadap pengguna mobile messaging di kota Bandung)."

Adapun tujuan penelitian ini untuk memperoleh informasi mengenai: 1)Untuk memperoleh informasi mengenai tanggapan responden terhadap Faktor individu pada produk mobile messaging Blackberry Messanger, WhatsApp, KakaoTalk, Line dan WeChat 2)Untuk memperoleh informasi mengenai tanggapan konsumen terhadap Faktor sosial pada produk mobile messaging Blackberry Messanger, WhatsApp, KakaoTalk, Line dan WeChat.3)Untuk memperoleh informasi mengenai tanggapan responden terhadap Keputusan menggunakan pada produk mobile messaging Blackberry Messanger WhatsApp, KakaoTalk, Line dan WeChat. 4)Untuk memperoleh informasi mengenai besarnya pengaruh faktor individu dan sosial terhadap tingkat keputusan menggunakan pada produk Blackberry Messanger, WhatsApp, KakaoTalk, Line dan WeChat.

\section{KAJIAN PUSTAKA}

Untuk mendapatkan pelanggan, perusahaan perlu memperhatikan berbagai faktor, salah satunya consumer behavior atau perilaku konsumen yang bertujuan agar perusahan dapat menyusun program pemasaran yang sesuai dengan tuntutan pasar, serta mampu bersaing secara competitive advantages untuk mencapai superior performancee dibandingkan dengan competitor dalam unit bisnis yang sama. Menurut, Schiffman dan Kanuk (2010:23), "Consumer behaviour is focuses on the behavior that consumers display in searching for, purchasing, using evaluating, and disposing of products and services that they expect will satisfy their needs".

Perilaku konsumen yang satu dengan yang lainnya pasti berbeda dikarenakan kebutuhan dan keinginan akan product masingmasing individu berbeda. Menurut Engel, Blackwell dan Miniard dalam Hawkins (2004:130), perilaku konsumen terbentuk dari tiga bagian yaitu individual react, socio-cultural environment, dan organization marketing.

Seorang individu memiliki karakteristik di dalam memilih product (barang dan jasa) yang akan digunakan. Karakteristik itu dapat dipengaruhi dan dilihat dari berbagai segi yaitu internal (personal influences) yang terbentuk melalui Individual React menurut Homer dan Kahle (1988) hal tersebut masuk kedalam Internal Oriented maupun eksternal (social influences) yang terbentuk dari Sociocultural Environment Homer dan Kahle (1988) mengemukakan bahwa social influence tersebut termasuk kedalam Eksternal Oriented, dalam artian konsumen sebelum memilih untuk menggunakan atau membeli suatu product akan dipengaruhi atau termotivasi oleh hal tersebut, seperti yang dikemukakan Jobber (2010) bahwa konsumen dapat dipengaruhi oleh perilaku 
pembeliannya yang dapat digambarkan sebagai berikut :

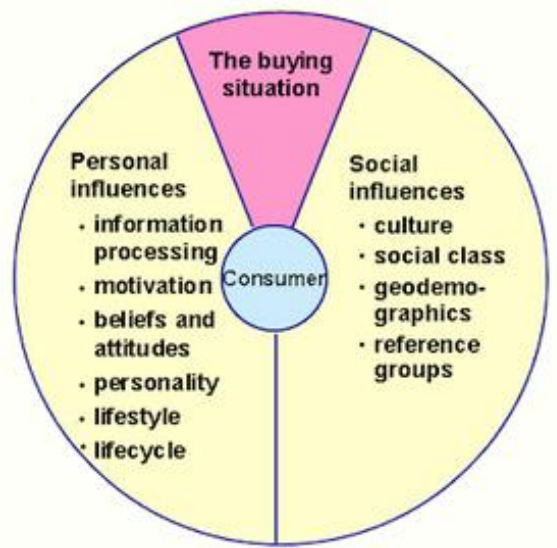

Sumber : David Jobber (2010)

GAMBAR 1

\section{INFLUENCES ON CONSUMER} PURCHASING BEHAVIOUR

Perilaku konsumen erat kaitannya dengan bagaimana perilaku konsumen akhir membeli atau mengkonsumsi suatu produk untuk memenuhi kebutuhannya. Dalam perilaku pembelian, konsumen mengalami proses keputusan pembelian didalamnya dipengaruhi oleh pengaruh eksternal (pengaruh luar) dan pengaruh dari dalam dirinya (perbedaan individu dan proses psikologis). Sehingga perilaku konsumen dapat diartikan sebagai semua tindakan, serta proses psikologis yang mendorong tindakan tersebut saat sebelum membeli, ketika membeli, menggunakan, menghabiskan produk dan jasa setelah melakukan hal tersebut lalu melakukan evaluasi.

Faktor individu merupakan faktor pembentuk dari perilaku konsumen (consumer behavior). Setiap perusahaan perlu memperhatikan faktor pembentuk ini yang dapat dijadikan sebagai referensi dalam membuat suatu product. Walaupun faktor individu tidak dapat dijangkau oleh perusahaan, dengan menawarkan product atau jasa yang sesuai dengan keinginan individu, maka product yang ditawakan akan disukai. Sciffman dan Kanuk (2010:104) yang menyatakan bahwa, perilaku individu menunjukkan pengaruh yang membentuk perilaku berkonsumsi individu. Jobber (2010) mengemukakan faktor yang mempengaruhi individu adalah information processing, motivation, belief and attitudes, personality, life style, and life cycle. Sumber informasi, motivasi, percaya dan sikap, personal, gaya hidup, serta siklus hidup.

Faktor sosial merupakan faktor dari pembentukan perilaku konsumen dalam menggunakan dan membeli barang yang dipengaruhi oleh lingkungannya yang dapat merubah pola perilaku individu orang lain. Peneliti mengambil konsep yang dikemukakan oleh Schiffman dan Kanuk (2010:318) bahwa, konsumen diciptakan oleh lingkungan mereka dan juga beroperasi di dalam lingkungan. Pembentuk factor sosial yaitu culture, social class, geo demographics, reference groups (Jobber 2010).

Sebelum melakukan keputusan menggunakan konsumen dihadapkan dengan beberapa tahapan. Adapun tahapan keputusan menggunakan itu adalah titik tolak untuk memahami perilaku pengguna yang merupakan model rangsangan-tanggapan. Rangsangan pemasaran dan lingkungan mulai memasuki kesadaran pembeli. Karakteristik pembeli dan proses pengambilan keputusan menimbulkan keputusan menggunakan tertentu. Adapun model perilaku konsumen yang dikemukakan oleh Kotler dan Keller (2012:166) terdiri dari Problem Recognation, Information Search, Evaluaition of Alternatives, Purchase Decision, dan Post Purchase Behavior.

Jobber (2010) yang menjelaskan bahwa saat seseorang dalam melakukan keputusan menggunakan, peranan tersebut terdiri dari :

1. Initiator - the person who begins the process of considering a purchase. Information may be gathered by this person to help the decision. Inisiator - orang yang memulai proses mempertimbangkan pembelian.

2. Influencer - the person who attempts to persuade others in the group concerning the outcome of the decision. Influencers typically gather information and attempt to improve their choice criteria on the decision. Orang yang berusaha untuk membujuk orang lain dalam kelompok mengenai hasil keputusan.

3. Decider - the individual with the power and/or financial authority to make the ultimate choice which product to buy. Individu dengan kekuatan dan atau kewenangan keuangan untuk membuat pilihan utama untuk membeli produk.

4. Buyer - the person who conducts the transaction. The buyer calls the supplier, visits the store, makes the payment and effects delivery. Orang yang melakukan transaksi.

5. User - the actual consumer/user of the product. - konsumen atau pengguna yang sebenarnya produk.

Kawee Boonlertvanic (2009:58) mengemukakan bahwa, pengambilan keputusan konsumen didefinisikan sebagai pola perilaku konsumen itu dilanjutkan, menentukan dan mengikuti proses pengambilan keputusan untuk akuisisi kebutuhan memuaskan produk, ide atau jasa. Peneliti mengambil dimensi yang 
dikemukakan oleh penelitian sebelumnya dengan judul the myth of ethical consumer do ethics (2013:3) yang mengungkapkan bahwa dimensi keputusan menggunakan adalah fashion trends, price, value, and brand image (Marylyn Carrigan dan Ahmad Atala, 2001:569).

Perilaku konsumen melibatkan lebih dari sekedar membeli, di dalam pemasaran keputusan untuk membeli merupakan hal yang penting namun, menggunakan merupakan bagian dari membeli seperti yang dikemukakan oleh Hoyer dan Maccinis (2010:4) bahwa, "Buying represents one type of acquisition behavior, acquisition includes other ways of obtaining goods and services, such as leasing, trading, and sharing. It also involves decisions about time as well as money. After consumers acquire an offering, they use it, which is why usage is at the very core of consumer behavior".

Hubungan antara faktor individu dan sosial terhadap keputusan menggunakan ini sesuai dengan penelitian sebelumnya Rokeach, 1973 yang mengungkapkan bahwa "The consumer's ethical decision making is influenced by individual factors such as social attitudes (philosophies of human nature)". Pengambilan keputusan etis konsumen dipengaruhi oleh faktor individu seperti sikap sosial (filsafat sifat manusia).

Penelitian ini menggunakan pendekatan manajemen pemasaran khususnya mengenai pengaruh faktor individu dan sosial terhadap keputusan menggunkan aplikasi mobile messaging di Kota Bandung.

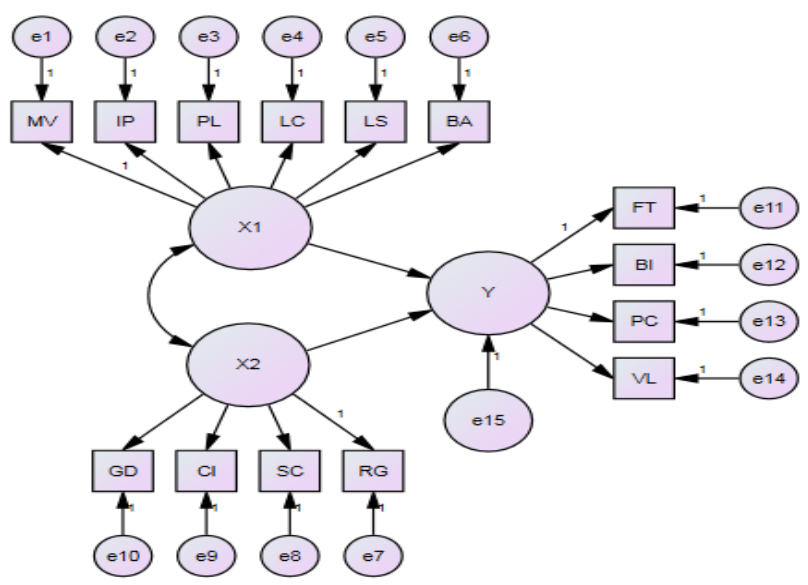

GAMBAR 2

PARADIGMA PENELITIAN

Keterangan, $\mathrm{X}_{1}$ : Faktor Individu, $\mathrm{M}\left(\mathrm{X}_{1.1}\right)$ Motivation, IP $\left(\mathrm{X}_{1.2}\right)$ Information Processing, $\mathrm{PL}\left(\mathrm{X}_{1.3}\right) \quad$ Personality, LC $\left(\mathrm{X}_{1.4}\right)$ Life Cycle, LS $\left(\mathrm{X}_{1.5}\right)$ Life Style, BA $\left(\mathrm{X}_{1.6}\right)$ Belief and attitudes. $\mathrm{X}_{2}$ : Faktor Sosial $\mathrm{GD}\left(\mathrm{X}_{2.1}\right)$ Geo Demographics, CL $\left(\mathrm{X}_{2.2}\right)$ Culture, $\mathrm{SC}\left(\mathrm{X}_{2.3}\right)$ Social class, $\mathrm{RG}\left(\mathrm{X}_{2.4}\right) \quad$ Reference Groups. Y : Keputusan Menggunakan,
$\mathrm{FT}\left(\mathrm{Y}_{1}\right)$ Fashion Trends, $\mathrm{BI}\left(\mathrm{Y}_{2}\right)$ Brand Image, $\mathrm{PC}\left(\mathrm{Y}_{3}\right)$ Price $\mathrm{VL}\left(\mathrm{Y}_{4}\right) \quad$ Value.

\section{METODE PENELITIAN}

Adapun yang menjadi objek penelitian sebagai variabel bebas (eksogen) adalah Faktor Individu $\left(\mathrm{X}_{1}\right)$, dengan indikator Motivation, Information Processing, Personality, Life Cycle, Life Style, Belief and attitudes dan Faktor Sosial $\left(\mathrm{X}_{2}\right)$ dengan indikator Geo Demographics, Culture, Social class, Reference Groups. Kemudian objek penelitian yang menjadi variabel terikat (endogen) adalah keputusan menggunakan (Y) yang meliputi Fashion Trends, Brand Image, Price, Value. Objek yang dijadikan responden dalam penelitian ini adalah pengguna Aplikasi Mobile Messaging di Kota Bandung.

Penelitian ini dilakukan pada kurung waktu kurang dari satu tahun, maka penelitian ini menggunakan metode cross sectional method. Berdasarkan tingkat penjelasan dan bidang penelitian, maka jenis penelitian ini adalah penelitian deskriptif dan verifikatif, dengan metode penelitian yang digunakan adalah explanantory survey. Populasi dalam penelitian ini adalah pengguna mobile messaging di Kota Bandung dengan kelompok masyarakat yang mengakses melalui paket data (internet) 22,1\% melalui smartphone dari jumlah penduduk sebesar 2.620.000 jiwa, dengan jumlah $\mathrm{N}=579.000$. Pengmbilan sampling menggunakan simple random sampling dari jumlah populasi sebanyak 400 orang.

Secara statistik, hipotesis yang akan diuji dalam rangka pengambilan keputusan penerimaan atau penolakan hipotesis dapat dirumuskan sebagai berikut:

1. Hipotesis 1

$\mathrm{H}_{0}$ c.r $\leq 0,05$ artinya tidak terdapat pengaruh antara faktor individu dengan keputusan menggunakan

2. Hipotesis 2

$\mathrm{H}_{1}$ c.r $\geq 0,05$ artinya terdapat pengaruh antara faktor individu dengan keputusan menggunakan 3. Hipotesis 3

$\mathrm{H}_{0}$ c.r $\leq 0,05$ artinya tidak terdapat pengaruh antara faktor sosial dengan keputusan menggunakan

4. Hipotesis 4

$\mathrm{H}_{2}$ c.r $\geq 0,05$ artinya terdapat pengaruh antara faktor sosial dengan keputusan menggunakan

5. Hipotesis 5

$\mathrm{H}_{0}$ c.r $\leq 0,05$ artinya tidak terdapat pengaruh antara faktor individu dan sosial dengan keputusan menggunakan

6. Hipotesis 6 
$\mathrm{H}_{3}$ c.r $\geq 0,05$ artinya terdapat pengaruh antara faktor individu dan sosial dengan keputusan menggunakan

\section{HASIL PENELITIAN \\ PEMBAHASAN}

DAN

1. Pembahasan Deskriptif

a. Faktor Individu

Berdasarkan hasil penelitian yang bersifat empirik mengenai faktor individu yang dihasilkan temuan bahwa dimensi faktor individu yang memberikan kontribusi tinggi yaitu personality dalam faktor individu pengguna aplikasi mobile messaging.

\section{b. Faktor Sosial}

Berdasarkan hasil penelitian yang bersifat empirik mengenai faktor sosial yang dihasilkan temuan bahwa dimensi faktor sosial yang memberikan kontribusi tinggi yaitu reference groups dalam faktor sosial pengguna aplikasi mobile messaging..

\section{c. Keputusan Menggunakan}

Berdasarkan hasil penelitian yang bersifat empirik mengenai keputusan menggunakan yang dihasilkan temuan bahwa dimensi value telah memberikan kontribusi tinggi dalam keputusan menggunakan aplikasi mobile messaging.

\section{Pembahasan Verifikatif}

Dengan menggunakan program AMOS 22.0 for Windows, diperoleh hasil structural equation model pengujian ini dilakukan untuk mengukur seberapa besar pengaruh faktor individu yang terdiri dari $\mathrm{M}\left(\mathrm{X}_{1.1}\right)$ Motivation, IP $\left(\mathrm{X}_{1.2}\right)$ Information Processing, PL $\left(\mathrm{X}_{1.3}\right)$ Personality, $\mathrm{LC}\left(\mathrm{X}_{1.4}\right) \quad$ Life Cycle, $\mathrm{LS}\left(\mathrm{X}_{1.5}\right)$ Life Style, BA ( $\left.\mathrm{X}_{1.6}\right)$ Belief and attitudes, factor sosial yang terdiri $\mathrm{GD}\left(\mathrm{X}_{2.1}\right)$ Geo Demographics, CL $\left(\mathrm{X}_{2.2}\right)$ Culture, SC $\left(\mathrm{X}_{2.3}\right)$ Social class, $\mathrm{RG}\left(\mathrm{X}_{2.4}\right)$ Reference Groups, terhadap keputusan menggunakan yang terdiri dari $\mathrm{FT}\left(\mathrm{Y}_{1}\right)$ Fashion Trends, $\mathrm{BI}\left(\mathrm{Y}_{2}\right)$ Brand Image, $\mathrm{PC}\left(\mathrm{Y}_{3}\right)$ Price $\mathrm{VL}\left(\mathrm{Y}_{4}\right)$ Value, serta untuk mengetahui indicator yang memberikan kontribusi tinggi pada masing-masing faktor.

Pengukuran model secara keseluruhan, tahap pertama dari uji kecocokan ini ditujukan untuk mengevaluasi secara umum derajat kecocokan atau Goodness Of Fit (GOF) antara data dengan model di dapatkan hasil pada Tabel 1 berikut ini :

TABEL 1

PENGUJIAN MODEL PENELITIAN

\begin{tabular}{|c|c|c|c|c|}
\hline \multirow{2}{*}{ No } & $\begin{array}{c}\text { Goodness } \\
\text {-of-Fit } \\
\text { Measures }\end{array}$ & $\begin{array}{c}\text { Cut-off } \\
\text { value }\end{array}$ & Hasil & $\begin{array}{c}\text { Evaluasi } \\
\text { Model }\end{array}$ \\
\hline \multicolumn{5}{|c|}{ Basic Goodness of Fit } \\
\hline \multirow{4}{*}{1} & $\begin{array}{c}\text { Chi- } \\
\text { square } \\
\left(X^{2}\right)\end{array}$ & $\begin{array}{c}\text { Sekecil } \\
\text { Mungkin } \\
\text { (good fit })\end{array}$ & 142.5 & Good Fit \\
\hline
\end{tabular}

\begin{tabular}{|c|c|c|c|c|}
\hline No & $\begin{array}{l}\text { Goodness } \\
\text {-of-Fit } \\
\text { Measures }\end{array}$ & $\begin{array}{c}\text { Cut-off } \\
\text { value }\end{array}$ & Hasil & $\begin{array}{c}\text { Evaluasi } \\
\text { Model }\end{array}$ \\
\hline 2 & $\begin{array}{c}\text { Derajat } \\
\text { Kebebasa } \\
n\end{array}$ & \multicolumn{3}{|c|}{74} \\
\hline 3 & $\begin{array}{c}\text { Probabilit } \\
y\end{array}$ & $\geq 0,05$ & 0.000 & $\begin{array}{c}\text { Model Not } \\
\text { Fit }\end{array}$ \\
\hline \multicolumn{5}{|c|}{ Absolute Fit Measures } \\
\hline 4 & CMIN/ df & $\leq 2,00$ & 1.927 & Good Fit \\
\hline 5 & GFI & $\begin{array}{c}\geq 0.90 \\
(\text { good fit }) \\
0.80 \leq \\
\text { GFI }< \\
0.90 \\
(\text { marginal } \\
\text { fit })\end{array}$ & 0.949 & Good Fit \\
\hline 6 & RMR & $\begin{array}{c}\leq 0.05 \\
(\text { good fit })\end{array}$ & 0.109 & $\begin{array}{c}\text { Model Not } \\
\text { Fit }\end{array}$ \\
\hline 7 & RMSEA & $\begin{array}{c}<0.08 \\
\text { (close fit) }\end{array}$ & 0.048 & Good Fit \\
\hline 8 & ECVI & $\begin{array}{l}\text { Sekecil } \\
\text { mungkin } \\
(\text { good fit })\end{array}$ & 0,510 & Good Fit \\
\hline 9 & PGFI & $\begin{array}{c}\text { PGFI < } \\
\text { GFI } \\
(0,732< \\
0,905) \text {, } \\
\text { semakin } \\
\text { rendah } \\
\text { semakin } \\
\text { baik }\end{array}$ & 0,669 & Good Fit \\
\hline \multicolumn{5}{|c|}{ Incremental Fit Measures } \\
\hline 10 & TLI & $\begin{array}{c}\geq 0.90 \\
(\text { good fit }) \\
0.80 \leq \\
\text { TLI }< \\
0.90 \\
\text { (marginal } \\
\text { fit) }\end{array}$ & 0.813 & $\begin{array}{c}\text { Marginal } \\
\text { Fit }\end{array}$ \\
\hline 11 & NFI & $\begin{array}{c}\geq 0.90 \\
(\text { good fit }) \\
0.80 \leq \\
\mathrm{NFI}< \\
0.90 \\
(\text { marginal } \\
\text { fit })\end{array}$ & 0.737 & $\begin{array}{c}\text { Model Not } \\
\text { Fit }\end{array}$ \\
\hline 12 & RFI & $\begin{array}{c}\geq 0.90 \\
(\text { good fit }) \\
0.80 \leq \\
\mathrm{RFI}< \\
0.90 \\
(\text { marginal } \\
\text { fit })\end{array}$ & 0.677 & $\begin{array}{c}\text { Model Not } \\
\text { Fit }\end{array}$ \\
\hline 13 & IFI & $\begin{array}{c}\geq 0.90 \\
(\text { good fit }) \\
0.80 \leq \mathrm{IFI} \\
<0.90 \\
(\text { marginal } \\
\text { fit) }\end{array}$ & 0.854 & $\begin{array}{c}\text { Marginal } \\
\text { Fit }\end{array}$ \\
\hline 14 & CFI & $\begin{array}{c}\geq 0.90 \\
\text { (good fit) } \\
0.80 \leq \\
\mathrm{CFI}< \\
0.90\end{array}$ & 0.848 & $\begin{array}{c}\text { Marginal } \\
\text { Fit }\end{array}$ \\
\hline
\end{tabular}




\begin{tabular}{|c|c|c|c|c|}
\hline No & $\begin{array}{l}\text { Goodness } \\
\text {-of-Fit } \\
\text { Measures }\end{array}$ & $\begin{array}{c}\text { Cut-off } \\
\text { value }\end{array}$ & Hasil & $\begin{array}{c}\text { Evaluasi } \\
\text { Model }\end{array}$ \\
\hline & & $\begin{array}{c}\text { (marginal } \\
\text { fit) }\end{array}$ & & \\
\hline \multicolumn{5}{|c|}{ Parsimonious Fit Measures } \\
\hline 15 & PNFI & $\begin{array}{l}\text { Semakin } \\
\text { tinggi } \\
\text { semakin } \\
\text { baik, } \\
\text { dibanding } \\
\text { kan } \\
\text { dengan } \\
\text { alternatif } \\
\text { model }\end{array}$ & 0.600 & Good Fit \\
\hline 16 & AIC & $\begin{array}{c}\text { Kecil, } \\
\text { Mendekati } \\
\text { nilai } \\
\text { saturated } \\
\text { AIC (good } \\
\text { fit) } \\
\text { Saturated } \\
\text { AIC: } \\
210.000\end{array}$ & $\begin{array}{c}204.5 \\
90\end{array}$ & Good Fit \\
\hline 17 & CAIC & $\begin{array}{c}\text { Kecil, } \\
\text { Mendekati } \\
\text { nilai } \\
\text { saturated } \\
\text { CAIC } \\
\text { menunjuk } \\
\text { kan good } \\
\text { fit } \\
\text { Saturated } \\
\text { CAIC } \\
734.627\end{array}$ & $\begin{array}{c}626.7 \\
26\end{array}$ & $\begin{array}{c}\text { Model Not } \\
\text { Fit }\end{array}$ \\
\hline
\end{tabular}

Sumber : Hasil Pengolahan Data 2014

Berdasarkan Tabel tersebut diketahui Chi-Square sebesar 142.5 dengan derajat bebas 74 dan $p$-value sebesar $0,000>\alpha(=0,05)$ sehingga mengisyaratkan bahwa model teoritis dan konseptual pada diagram jalur didukung oleh data empirik, sehingga dapat diterima pada taraf signifikansi 5\%.

Tahap selanjutnya yaitu model pengukuran faktor yang menggambarkan hubungan antara variabel laten dengan indikator-indikatornya, diperoleh hasil bahwa nilai varience extract pada variabel Faktor Individu sebesar 0,960, untuk variabel Faktor Sosial sebesar 0,936, dan untuk variabel Keputusan Menggunakan sebesar 0,933. Nilai variance extract dari ketiga variabel melebihi nilai 0,50 yang direkomendasikan. Berdasarkan hal tersebut dapat dikatakan bahwa ketiga variabel laten dalam penelitian ini adalah reliable dan terdapat saling pengaruh yang signifikan.

Selanjutnya, structural model yang menggambarkan hubungan antar variabelvariabel laten atau antar variabel eksogen dengan variabel laten. Dalam tahapan ini yang harus dilakukan yaitu mendefinisikan hubungan kausal diantara variabel-variabel laten tersebut, yaitu faktor individu yang dipengaruhi oleh faktor sosial, faktor sosial yang dipengaruhi oleh faktor individu, dan keputusan menggunakan yang dipengaruhi oleh faktor individu dan faktor sosial.

Hasil pengujian secara parsial, antara faktor individu terhadap keputusan menggunakan memberikan hasil pada Gambar 1 berikut ini

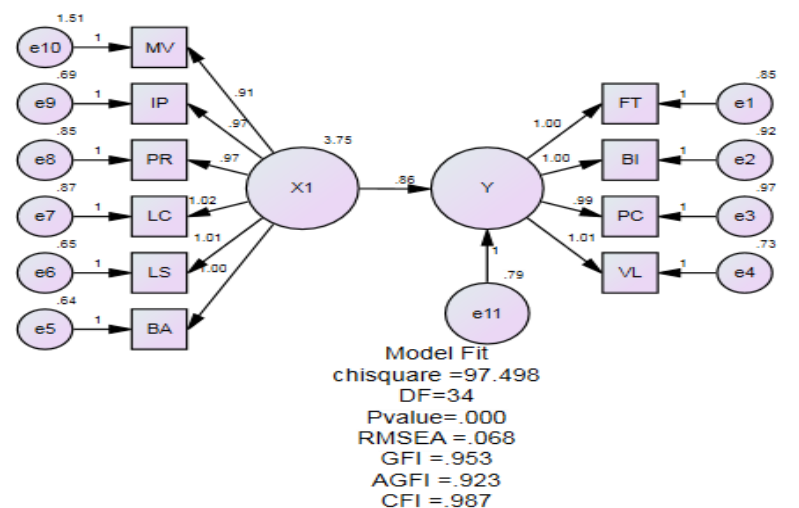

GAMBAR 1

DIAGRAM JALUR TAKSIRAN

PARAMETER FAKTOR INDIVIDU

TERHADAP KEPUTUSAN MENGGUNAKAN

Dengan membandingkan setiap goodness of fit dengan nilai probability 0.000 , nilai chi-square 97.498 , nilai TLI $0,626 \geq 0,90$, nilai GFI $0,953 \geq 0,90$, nilai AGFI $0,923 \geq$ 0,90 , nilai CFI $0,987 \geq 0,90$. Hasil yang diperoleh menunjukkan bahwa sebagian taksiran parameter pada diagram jalur tersebut adalah signifikan, terdapat beberapa hasil yang kurang signifikan seperti RMSEA, dan TLI, namun dapat dikatakan model tersebut sudah fit, seperti yang dikemukakan oleh Maholtra (2010:733) sebelumnya bahwa gunakan paling sedikit 1 ukuran yang bersifat absolute baik (misalnya : GFI, AGFI), 1 ukuran yang bersifat absolute buruk (misalnya Chi-Square, RMSR, SRMR, RMSEA) dan 1 ukuran yang bersifat komparatif (misalnya: NFI, NNFI, CFI, TLI, RNI) terlihat seluruh ukuran Goodness-of-Fit lebih besar dari cut-off-value, maka dapat dikatakan bahwa model penelitian pada Structural Equation Model (SEM) sudah fit. Hasil tersebut menggambarkan bahwa model mendukung teori yang telah ada.

Sama dengan yang telah dikemukakan sebelumnya di dapatkan hasil pengujian secara parsial antara faktor sosial terhadap keputusan menggunakan bahwa, dengan membandingkan setiap goodness of fit dengan nilai probability 0,111, nilai CMIN/DF $1.408 \leq 2,00$, nilai RMSEA $0,032 \leq 0,08$, nilai GFI $0,983 \geq 0,90$, nilai AGFI 0,967 $\geq 0,90$, nilai CFI 0,998 $\geq 0,90$. Hasil yang diperoleh menunjukkan bahwa semua taksiran parameter pada diagram jalur tersebut adalah signifikan, walaupun masih 
terdapat beberapa taksiran hasilnya tidak sesuai, namun dapat dikatakan bahwa model penelitian pada Structural Equation Model (SEM) sudah fit, terdapat pada Gambar 2 berikut ini :

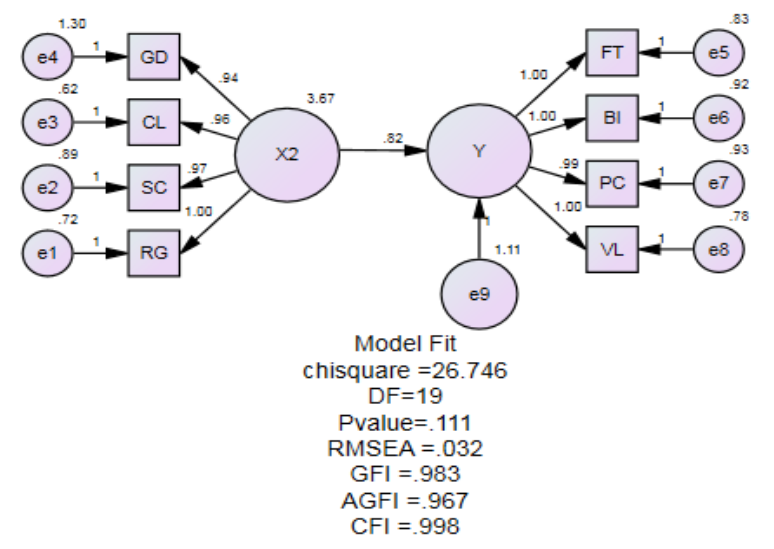

GAMBAR 2

DIAGRAM JALUR TAKSIRAN PARAMETER

FAKTOR SOSIAL TERHADAP KEPUTUSAN MENGGUNAKAN

Secara simultan terdapat pengaruh antara faktor individu dan sosial terhadap keputusan menggunakan aplikasi mobile messaging di Kota Bandung, yang di gambarkan pada Gambar 4 berikut ini :

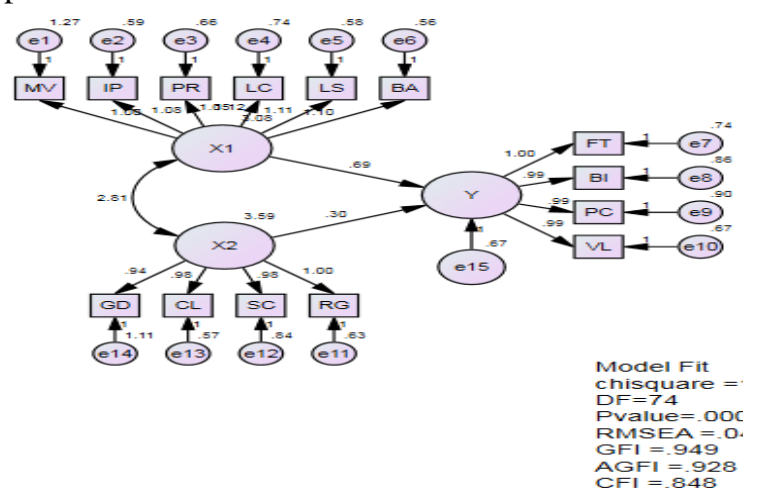

\section{GAMBAR 3 \\ DIAGRAM JALUR TAKSIRAN PARAMETER \\ FAKTOR INDIVIDU DAN SOSIAL TERHADAP KEPUTUSAN MENGGUNAKAN}

Dengan membandingkan setiap goodness of fit dengan nilai probability 0,000, nilai CMIN/df $1,927 \leq 2,00$, nilai RMSEA $0,048 \leq 0,08$, GFI $0,949 \geq 0,90$, dan nilai AGFI $0,928 \geq 0,90$. Hasil yang diperoleh menunjukkan bahwa semua taksiran parameter pada diagram jalur tersebut adalah signifikan.

Melalui program statistik AMOS dapat dianalisis dan dihitung hasil bobot regresi antar variabel laten yang sering disebut sebagai estimasi loading factors atau lamda value. Selain itu derajat bebas atau degree of freedom (df), nilai C.R atau t-hitung juga dapat diketahui.
Berdasarkan signifikansi t-hitung dengan nilai probabilitas $(\mathrm{p})=0,05$. Hasil bobot regresi uji kausalitas sebagai berikut :

TABEL 2

EVALUASI BOBOT REGRESI UJI

KAUSALITAS

\begin{tabular}{|l|l|l|l|c|c|c|}
\hline \multicolumn{2}{|c|}{} & \multicolumn{2}{|c|}{ Estimate } & S.E. & C.R. & $\mathrm{P}$ \\
\hline $\mathrm{X}_{2}$ & $<->$ & $\mathrm{X}_{1}$ & 2.809 & .250 & 11.254 & $* * *$ \\
\hline $\mathrm{X}_{1}$ & $-->$ & $\mathrm{Y}$ & .690 & .065 & 10.554 & $* * *$ \\
\hline $\mathrm{X}_{2}$ & $-->$ & $\mathrm{Y}$ & .296 & .057 & 5.232 & $* * *$ \\
\hline
\end{tabular}

Sumber : Hasil Pengolahan Data 2014

Besarnya pengaruh masing-masing variabel laten secara langsung (standardize direct effect) maupun tidak langsung (standardize indirect effect) serta efek total (standardizes total effect) diringkas dalam tabel sebagai berikut :

TABEL 3

EFEK LANGSUNG, EFEK TIDAK LANGSUNG, DAN EFEK TOTAL (STANDARDIZE)

\begin{tabular}{|l|c|c|c|c|c|c|}
\hline \multicolumn{1}{|c|}{ Variabel } & \multicolumn{3}{c|}{ F. Individu } & \multicolumn{3}{c|}{ F. sosial } \\
\hline & Langsung & $\begin{array}{l}\text { Tdk } \\
\text { lansung }\end{array}$ & Total & Langsung & $\begin{array}{l}\text { Tdk } \\
\text { lansung }\end{array}$ & Total \\
\hline F. Sosial & - & - & - & - & - & - \\
\hline $\begin{array}{l}\text { Keputusan } \\
\text { Menggunakan }\end{array}$ & 0,625 & 0,000 & 0,625 & 0,306 & 0,000 & 0,306 \\
\hline
\end{tabular}

Sumber : Hasil Pengolahan Data 2014

Secara keseluruhan model konseptual persamaan struktural yang dirancang berdasarkan goodness of fit atau pengujian model penelitian memenuhi kelayakan model (fit) yang berarti sesuai dengan kondisi empiris. Model penelitian secara teoritis merupakan adaptasi dari konsep consumer behavior. Sesuai model penelitian, faktor individu berpengaruh positif terhadap faktor sosial, baik secara langsung maupun tidak langsung, serta faktor individu berpengaruh positif terhadap keputusan menggunakan langsung maupun tidak langsung, dan faktor sosial berpengaruh terhadap keputusan menggunakan langsung maupun tidak langsung. Atas dasar analisis regression weight yang dilakukan, ditemukan uji-t atas variabel-variabel menunjukkan ditolaknya hipotesis nol dan diterimanya hipotesis alternatif.

TABEL 4

HASIL ANALISIS DATA ATAS DASAR REGRESSION WEIGHTS

\begin{tabular}{|l|l|}
\hline Hipotesis & Hasil Analisis \\
\hline $\begin{array}{l}\mathrm{H} 1: \text { Faktor Individu } \\
\text { berpengaruh positif pada } \\
\text { Faktor Sosial }\end{array}$ & $\mathrm{H} 1:$ diterima \\
\hline $\begin{array}{l}\mathrm{H} 2: \text { Faktor Individu } \\
\text { berpengaruh positif pada } \\
\text { Keputusan Menggunakan }\end{array}$ & $\mathrm{H} 2:$ diterima \\
\hline $\begin{array}{l}\mathrm{H} 3 \text { : Faktor Sosial } \\
\text { berpengaruh positif pada } \\
\text { Keputusan Menggunakan }\end{array}$ & $\mathrm{H} 3:$ diterima \\
\hline
\end{tabular}

Sumber : Hasil Pengolahan Data 2014 
Berdasarkan Tabel 4. di atas hipotesis penelitian dinyatakan diterima, karena sesuai dengan kriteria penerimaan hipotesis yaitu nilai Critical Ratio (C.R.) $\geq 1,967$ atau nilai probabilitas $(\mathrm{P}) \leq 0,05$ maka $\mathrm{H}_{0}$ ditolak (hipotesis penelitian diterima).

\section{KESIMPULAN DAN REKOMENDASI KESIMPULAN}

1. Hasil penelitian menyatakan bahwa, gambaran mengenai faktor individu pengguna aplikasi mobile messaging dapat dilihat dari dimensi-dimensinya yang terdiri dari motivation, information processing, personality, life cycle, life style, dan belief and attitudes berada pada kategori sedang. Hal ini menunjukkan bahwa persepsi menurut pengguna aplikasi mobile messaging di Kota Bandung menilai faktor individu memberikan pengaruh yang cukup baik. Dimensi personality merupakan dimensi yang memiliki penilaian paling tinggi dalam mepengaruhi keputusan menggunakan aplikasi mobile messaging, sedangkan dimensi yang memiliki penilaian paling rendah dalam mempengaruhi keputusan menggunakan adalah information processing

2. Hasil penelitian menyatakan bahwa, gambaran mengenai faktor sosial pengguna aplikasi mobile messaging dapat dilihat dari dimensi-dimensinya yang terdiri dari geodemographics, culture, social class, dan reference groups berada pada kategori sedang. Hal ini menunjukkan bahwa persepsi menurut pengguna aplikasi mobile messaging di Kota Bandung menilai faktor sosial memberikan pengaruh yang cukup baik. Dimensi reference groups merupakan dimensi yang memiliki penilaian paling tinggi dalam mempengaruhi keputusan menggunakan, sedangkan dimensi yang memiliki penilaian paling rendah dalam mempengaruhi keputusan menggunakan adalah culture.

3. Hasil penelitian menyatakan bahwa, gambaran keputusan menggunakan pada pengguna aplikasi mobile messaging di Kota Bandung yang diukur berdasarkan fashion trends, brand image, price, dan value secara keseluruhan berada pada kategori sangat tinggi. Artinya penerapan fashion trends, brand image, price dan value terhadap pengguna aplikasi mobile messaging di Kota Bandung berjalan dengan cukup baik. Dimensi value secara keseluruhan memiliki nilai paling tinggi, sedangkan untuk dimensi yang memiliki nilai terendah adalah fashion trends.
4. Faktor Individu memiliki pengaruh yang positif terhadap keputusan menggunakan aplikasi mobile messaging di Kota Bandung dengan nilai pengaruh langsung sebesar 0,625 atau $62.5 \%$, hasil ini diperoleh melalui uji model pada structural equation model melalui AMOS versi 22,0, sedangkan faktor sosial memiliki pengaruh positif terhadap keputusan menggunakan aplikasi mobile messaging di Kota Bandung dengan nilai pengaruh langsung sebesar 0,306 atau 30.6\%. Berdasarkan hal tersebut faktor individu memiliki pengaruh yang cukup besar pada keputusan menggunakan dibandingkan dengan faktor sosial, hal ini dikarenakan stimulus yang datang dari individu lebih besar dibandingkan dengan lingkungannya.

\section{REKOMENDASI}

1. Pengaruh Faktor Individu aplikasi mobile messaging di Kota Bandung secara menyeluruh memiliki pengaruh yang signifikan dan dikategorikan cukup baik pengaruhnya terhadap keputusan menggunakan, tetapi ada beberapa yang perlu dilakukan perbaikan yaitu pemrosesan informasi yang diberikan oleh perusahaan kepada pengguna, dalam hal information processing, terdapat beberapa pengguna yang kurang memahami dengan fitur yang ditawarkan oleh perusahaan aplikasi mobile messaging. perusahaan dapat melihat hal tersebut dengan memberikan pemahaman baik itu dalam peningkatan promosi yang dilakukan, menggunakan brand ambassador yang mampu menarik perhatian pengguna terhadap aplikasi mobile messaging. Perusahaan harus mampu meningkatkan penggunanya, serta mempertahankan pengguna lamanya dengan terus menawarkan fitur yang kreatif, inovatif, dan memberikan pemahaman yang tinggi.

2. Pengaruh Faktor Sosial pengguna aplikasi mobile messaging di Kota Bandung secara menyeluruh memiliki pengaruh signifikan dan dikategorikan cukup baik, sehingga terdapat beberapa yang perlu dilakukan yaitu budaya yang ada di lingkungan pangsa pasarnya, dikarenakan setiap budaya yang ada di setiap kawasan berbeda sehingga sebaiknya produk yang ditawarkan menyesuaikan dengan budaya, namun hal ini dirasakan cukup sulit maka sebaiknya menawarkan produk yang sesuai dengan budaya atau karakteristik secara objektif, menghindari hal yang dirasa negatif. Dengan memperhatikan beberapa hal tersebut diharapkan perusahaan aplikasi mobile messaging khususnya Blackberry Messanger, WhatsApp, Lne, KakaoTalk, 
dan WeChat mampu meningkatkan penggunanya.

3. Keputusan menggunakan pada pengguna aplikasi mobile messaging di Kota Bandung secara keseluruhan sudah cukup baik, namun hal ini harus dapat dipertahankan bahkan ditingkatkan terutama dalam hal fashion, komunikasi pada saat ini dapat dijadikan sebagai fashion, dimana setiap orang menggunakan aplikasi mobile messaging karena mengikuti trend komunikasi yang ada, perusahaan sebaiknya melihat hal tersebut sebagai suatu keuntungan dengan menerapkan berbagai macam program pemasaran yang sesuai dengan trend saat ini, terutama bagi perusahaan aplikasi mobile messaging Blackberry Messanger, WhatsApp, Line, KakaoTalk, dan WeChat.

4. Hasil penelitian menyatakan faktor individu dan sosial berpengaruh positif dan signifikan terhadap keputusan menggunakan, namun faktor sosial memberikan pengaruh langsung yang kecil dibandingkan dengan faktor individu. Maka penulis merekomendasikan perusahaan aplikasi mobile messaging khususnya Blackberry Messanger, WhatsApp, Line, KakaoTalk, dan WeChat memperhatikan kebutuhan dan keinginan pengguna, serta memperhatikan lingkungan sosial baik itu teman ataupun budaya dengan menawarkan fitur aplikasi yang sesuai, karena pada dasarnya manusia adalah makhluk sosial yang membutuhkan interaksi atau komunikasi satu sama lain.

\section{DAFTAR PUSTAKA}

Carrigan Marylyn, Ahmad Attala. 2001. The myth of ethical consumer do ethics matter in purchase behavior. Journal of consumer marketing. Vol 18. No 7 pp 560-576 ㅇ MCB University Press 07363761

Ferrell, O.C. And Gresham, Larry G. 1985. A Contigency Framework for Understanding Ethical Decision Making in Marketing. Journal of Marketing. Vol 49, pp 87-96

Hawkiins, Best \& Coney. 2004. Consumer Behavior Implication for Marketing Strategies. Boston: Richard Datwin. Inc

Homer, P. M., and Kahle, L. R. 1988. A Structural Equation Test of the ValueAttitude- Behavior Hierarchy. Journal of Personality and Social Psychology, 54, 638-646
Hoyer and Macinnis. 2010. Consumer Behaviour $5^{\text {th }}$ edition. USA: SouthWestern

Jobber, David, \& Lancaster, Geoff. 2010. Selling and Sales Management. (8th Edition). England : Prentice Hall.

Kawee Boonlertvanich. 2009. Journal Consumer Buying and Decision Making Behaviour of a Digital Camera in Thailand. RU. Int vol. 3(1)

Kotler, Phillip., \& Kevin, L. K. 2012. Marketing Management. USA: Pearson Education

Matin, Abdul, et al. "Balamuthia mandrillaris exhibits metalloprotease activities." FEMS Immunology \& Medical Microbiology 47.1 (2006): 8391.

Rokeach, M. 1973. The Nature of Human Values. New York: Free Press.

Schiffman, Leon G dan Lesli Laizer. 2010. Consumer Behaviour $10^{\text {th }}$ Edition. Pearson Prentice Hall 